\title{
Bem-Estar Pessoal nas Organizações: O Impacto de Configurações de Poder e Características de Personalidade ${ }^{1}$
}

\author{
Marina Campos Dessen ${ }^{2}$ \\ Maria das Graças Torres da Paz \\ Universidade de Brasilia
}

\begin{abstract}
RESUMO - Atualmente há um crescente interesse pelo bem-estar no trabalho, definido neste estudo como satisfação de necessidades e realização de desejos dos indivíduos ao desempenhar seu papel na organização. Como a literatura aponta a influência de características organizacionais e individuais no bem-estar ocupacional, esta pesquisa visa identificar o impacto das configurações de poder organizacional e das características de personalidade do Big Five nesta variável. A amostra possui 319 trabalhadores e suas respostas foram analisadas por meio de regressões. Os resultados apontam uma relação positiva entre as configurações sistema autônomo e missionária e bem-estar, e negativa entre instrumento e bem-estar, sendo essas duas últimas relações mediadas pela conscienciosidade. A discussão visa suscitar reflexões e estimular pesquisas futuras nesta área.
\end{abstract}

Palavras-chave: bem-estar nas organizações; poder organizacional; características de personalidade.

\section{Individual Well-being in Organizations: The Impact of Power Configurations and Personality Traits}

\begin{abstract}
There has been growing concern for well-being at the workplace, which is defined, in this study, as the satisfaction of needs and fulfillments of desires while working at the organization. Considering that the literature points out that both organizational and individual characteristics may influence occupational well-being, this research aims to identify the impact of organizational power configurations and of the Big Five personality traits on that variable. The sample has 319 workers and their responses were analyzed by means of regressions. The results indicate a positive relation between well-being and the missionary and autonomous system configurations, and a negative relation between well-being and instrument. The last two relations have been mediated by conscientiousness. The discussion tends to provoke reflections and stimulate future research in this area.
\end{abstract}

Keywords: well-being in the organizations; organizational power; personality traits.

O trabalho é de extrema importância para a vida dos indivíduos, contribuindo para a sua sobrevivência e adaptação ao mundo. Considerando que uma parcela significativa da vida do indivíduo é passada no ambiente de trabalho, torna-se essencial que ele se sinta bem em relação a este. Neste contexto, faz-se necessário intensificar as discussões e investigações de temas relativos ao bem-estar no trabalho, pois essa é uma área que ainda não possui concepções claras (Siqueira \& Padovam, 2008; Tamayo, 2004). Tais estudos podem contribuir para a criação de um ambiente mais saudável e propício à realização pessoal que, por sua vez, pode ter impacto em diversos setores da vida dos indivíduos e em variáveis da organização, como rotatividade, absenteísmo e desempenho (Danna \& Griffin, 1999; Warr, 2007).

As pesquisas envolvendo o bem-estar geral revelam a existência de duas correntes principais: a do bem-estar subjetivo (e.g. Diener, 1984) e a do bem-estar psicológico (e.g. Deci \& Ryan, 2008; Ryff, 1989). Com base nessas

1 Agradecemos ao CNPq pelo apoio financeiro recebido para a realização desta pesquisa.

2 Endereço para correspondência: SHIN QI 07 conjunto 05 casa 12, Lago Norte. Brasília, DF. CEP: 70515-050. Telefone: (61) 84348842 / 33682650.E-mail: ninadessen@gmail.com. abordagens, alguns autores criaram modelos que possibilitam a análise do bem-estar sob a perspectiva da Psicologia Social e do Trabalho. Esses autores acreditam que avaliar o bem-estar em contextos particulares, como o trabalho, é mais vantajoso do que avaliá-lo de uma maneira geral. Isso porque as relações de antecedentes do contexto de trabalho são mais fortes quando o bem-estar é avaliado nesse contexto, e não de maneira geral, contribuindo mais para a compreensão, a intervenção e a promoção dessa variável (Daniels, 2000; Van Horn \& cols. 2004; Warr, 2007).

No Brasil, Ferreira, Pacheco, Pinto, Fernandes e Silva (2007) afirmam que o bem-estar no trabalho é um construto superordenado que contém uma dimensão cognitiva, avaliada pela satisfação no trabalho, e uma dimensão afetiva, associada aos afetos positivos e negativos dirigidos ao trabalho. Por outro lado, Souto e Rego (2007) analisam somente os afetos; portanto, o construto reflete a frequência de experiências com afetos positivos e a escassez com experiências de afetos negativos.

Ainda no Brasil, Siqueira e Padovam (2008) consideram que o bem-estar no trabalho é formado por vínculos afetivos positivos com o trabalho (satisfação e envolvimento) e com a organização (comprometimento organizacional afetivo). Outra autora que trabalha com essa variável é Paschoal 
(2008), que o conceitua como a "prevalência de emoções positivas no trabalho e a percepção do indivíduo de que, no seu trabalho, expressa e desenvolve seus potenciais e avança no alcance de suas metas de vida" (p. 23). Dessa maneira, a autora inclui tanto aspectos afetivos, avaliados pelas emoções e humores, quanto cognitivos, representados pela realização.

Neste artigo, tenta-se delimitar o construto às organizações de trabalho, adotando-se a concepção de bem-estar proposta por Paz (2004), que define o fenômeno como sendo a satisfação de necessidades e a realização de desejos dos indivíduos ao desempenhar o seu papel na organização. Essa definição considera tanto aspectos afetivos quanto cognitivos, porém, os avalia por meio dos indicadores de bem-estar, fato que favorece o planejamento organizacional e permite implementar ações que produzem mais resultados (Diener, 2000; Meleiro \& Siqueira, 2005).

De acordo com Paz (2004), os indicadores de bem-estar são: Valorização do trabalho - percepção do próprio funcionário de que seu trabalho é importante, tanto para ele quanto para os outros (organização e sociedade); Reconhecimento pessoal - percepção do funcionário sobre ser admirado e recompensado por sua competência no trabalho; Autonomia - percepção do funcionário sobre a liberdade que possui para utilizar seu estilo pessoal na execução de seu trabalho; Expectativa de crescimento - percepção que ele possui da possibilidade de estar se desenvolvendo pessoal e profissionalmente; Suporte ambiental - percepção do funcionário sobre existência de apoio material, social e tecnológico; Recursos financeiros - percepção de justiça na relação entre o trabalho que realiza e o salário que recebe; e Orgulho - sentimento de orgulho por fazer parte daquela organização.

$\mathrm{Na}$ concepção de bem-estar pessoal adotada por Paz (2004), as relações de troca entre trabalhador e organização são consideradas. Essa forma de relação é uma marca do contrato estabelecido entre as partes: o trabalhador fornece sua força de trabalho para a organização em troca de um salário, de forma que a negociação é uma característica da relação. Assim, para a autora, o bem-estar decorre das relações de reciprocidade estabelecidas entre trabalhador e organização, sendo o bem-estar afetado por características individuais (Danna \& Griffin, 1999; Diener \& cols., 1999; Paz, 2004) e organizacionais (Gosendo \& Paz, prelo; Paz, 2004; Tamayo, 2004; Warr, 2007), relação que é objeto de estudo nesta pesquisa.

O poder é uma das variáveis consideradas de extrema importância para a compreensão das organizações (Martins \& Paz, 2000). Mintzberg (1983), um dos principais teóricos que estuda o poder nas organizações, busca compreender o comportamento da organização por meio do poder, conceituado como a capacidade de afetar resultados organizacionais e analisado nos níveis individual e coletivo, interno e externo, intra e entre grupos. Esse autor demarca o movimento do poder dentro e fora da organização por meio do desenvolvimento de seis configurações, decorrentes das inter-relações entre coalizões, sistema de metas e de influência e bases de poder. Para ele, todas as configurações podem estar presentes em uma organização; porém, há aquela que é mais característica, sendo esta passível de mudança devido aos estágios de desenvolvimento organizacional.
A configuração denominada 'autocracia' é aquela em que o poder é centrado em um influenciador (proprietário, líder poderoso) ou na cúpula da organização. A configuração 'missionária' tem a ideologia como principal influenciadora interna, favorecendo uma forte identificação dos membros com a missão ideológica da organização. Na configuração 'instrumento', a organização é um meio para que os mais fortes influenciadores, externos, alcancem seus objetivos, funcionando com uma estrutura burocratizada e controladora e com uma hierarquia rígida.

A configuração 'meritocracia' tem uma forte coalizão interna profissional, sendo os especialistas os que possuem maior poder na organização. Na configuração "sistema autônomo' (assim denominado por Paz, 2004, em substituição à denominação "sistema fechado"), o controle é feito por meio do estabelecimento de metas e são os próprios membros da organização que exercem o poder, principalmente administradores e analistas de apoio. A organização tenta evitar que influenciadores externos interfiram no seu cotidiano. Por fim, a configuração 'arena política' caracteriza a organização em crise, marcada por conflitos e interesses individualizados e de grupos. Pode ser transitória ou levar à morte da organização.

Segundo Mintzberg (1983), as organizações passam por estágios de desenvolvimento, daí a possibilidade de mudarem de configuração. A configuração autocrática caracteriza o estágio inicial da organização, pois para a sua criação e estruturação é necessário que haja maior centralização do poder. $\mathrm{O}$ período de desenvolvimento seguinte tem como possíveis representantes as configurações missionária ou instrumento. Algumas empresas podem passar para o estágio de maturidade, que corresponde ao sistema autônomo ou à meritocracia, sem necessariamente vivenciar o anterior. Há maior probabilidade de que essas configurações sobrevivam às crises, devido à maior capacidade que possuem de se renovarem. Por fim, a arena política pode fazer parte de todos os momentos de crise e transição de uma configuração para a outra. Caso a empresa não supere essa crise, poderá enfraquecer e desaparecer.

Admitindo que há uma relação entre configurações de poder e características individuais (Neiva, 1999) e que a subjetividade influencia o bem-estar do trabalhador nas organizações (Danna \& Griffin, 1999; Warr, 2007), torna-se necessário incorporar as características de personalidade ao modelo teórico. Para Paz (2004), assim como para Diener e cols. (1999), as características pessoais dos indivíduos podem ser moderadoras ou mediadoras do impacto que características da organização têm no bem-estar dos trabalhadores.

Nesta pesquisa, a identificação de características de personalidade dos indivíduos foi efetuada com base no modelo dos cinco grandes fatores (Big Five), uma vez que foi encontrada relação do mesmo com o bem-estar geral (Albuquerque, 2004). Esse modelo foi desenvolvido entre as décadas de 1920 e 1930 com base em diversos estudos que visavam analisar termos descritivos de traços de personalidade e com o objetivo de responder a seguinte questão: quais os principais fatores em que as pessoas variam?

Para Hutz e cols. (1998), os fatores do Big Five correspondem às dimensões humanas básicas que são encontradas de forma consistente e replicável em diversos estudos, inclusive 
naqueles realizados no Brasil (Allik \& McCrae, 2002; Andrade, 2008; Hutz \& cols., 1998; McCrae \& Terracciano, 2005). Portanto, esse é um modelo cuja descoberta foi acidental a partir de uma generalização empírica, não havendo explicação teórica a priori para a organização da personalidade nessas dimensões (Hutz \& cols., 1998).

Apesar de haver um maior consenso quanto à solução de cinco fatores, ainda existem divergências na área quanto à terminologia que deve ser utilizada no Big Five. No Brasil, Nunes, Hutz e Giacomoni (2009) indicam que os fatores têm sido denominados extroversão (extraversion), neuroticismo (neuroticism), abertura (openness), socialização ou amabilidade (agreeableness) e realização ou conscienciosidade (conscientiousness). Portanto, esses são os termos que serão utilizados neste estudo, já que se tratam dos mais utilizados no Brasil.

A extroversão se refere ao grau de tolerância à estimulação sensorial vinda de outras pessoas e situações, sendo relacionada ao número e à força das interações com outras pessoas e à capacidade de estar feliz. Seu alto grau significa que o indivíduo tende a ser sociável, ativo, otimista e envolvido com muitas atividades. O oposto são pessoas reservadas e quietas (Howard \& Howard, 1995).

O neuroticismo é o grau de sensibilidade ao estresse e de ajustamento emocional, que identifica indicadores de propensão ao sofrimento psicológico. Um nível alto significa maior ansiedade, depressão, impulsividade, hostilidade e ideias irreais. Um nível baixo indica que o indivíduo lida com o estresse de forma calma e segura (Howard \& Howard, 1995). Hutz e cols. (1998) afirmam que esse é um domínio bem conhecido da personalidade e que envolve, principalmente, características como afeto positivo e negativo, ansiedade e estabilidade emocional.

A abertura refere-se ao grau de abertura a novas experiências ou formas de fazer as coisas, estando relacionado a comportamentos de exploração. Pessoas com abertura elevada são curiosas, criativas e exploram bastante o ambiente, sendo o oposto pessoas convencionais, conservadoras e rígidas (Howard \& Howard, 1995). Segundo Hutz e cols. (1998), esse é um fator que considera a percepção da pessoa quanto à flexibilidade de pensamento, fantasia, imaginação, abertura para novas experiências e interesses culturais.

A socialização ou amabilidade indica a tendência do indivíduo a ser socialmente agradável, caloroso e dócil (Hutz $\&$ cols., 1998). Refere-se ao tipo de interação que uma pessoa mantém com as outras, estando relacionada ao grau em que esta defere ou se acomoda aos outros, que pode variar de compaixão a antagonismo. Elevados níveis significam tendências generosas, prestativas e altruístas; baixos níveis indicam pessoas cínicas, com tendências manipuladoras e vingativas (Howard \& Howard, 1995).

Por fim, a realização ou conscienciosidade agrupa características que se relacionam com a responsabilidade e a honestidade de um lado e a negligência e irresponsabilidade de outro (Hutz \& cols., 1998). Esse fator refere-se ao grau em que os indivíduos lutam por seus objetivos. Pessoas conscienciosas são mais organizadas, persistentes, decididas, ambiciosas e perseverantes. $\mathrm{O}$ contrário corresponde a pessoas descuidadas, negligentes e sem objetivos claros (Howard \& Howard, 1995).
Sendo assim, como a literatura aponta a possível relação entre características individuais e organizacionais e o bem-estar no trabalho, o presente estudo possui os seguintes objetivos: verificar em que medida as variáveis de configurações de poder explicam o bem-estar e analisar se há mediação das características de personalidade frente às relações existentes entre as configurações de poder e o bem-estar.

\section{Método}

\section{Participantes}

A amostra foi composta por 319 respondentes de duas organizações de Brasília, todos com mais de três meses de serviço nas mesmas. Essa amostra foi não probabilística e o critério de inclusão dos participantes foi a disponibilidade de cada um para preencher o questionário e devolvê-lo em tempo hábil ao pesquisador.

Desse total, 169 participantes trabalham em uma empresa privada, correspondendo a $38,5 \%$ da população de funcionários dessa empresa. As áreas administrativa e operacional estão representadas nessa amostra com mais de $10 \%$ de seus funcionários participando da pesquisa. Os outros 150 participantes fazem parte de uma empresa pública, totalizando $15 \%$ da sua população. A porcentagem de participantes por área não foi calculada devido a grande parte $(50,3 \%)$ da amostra ter deixado esse dado em branco no questionário.

As características dos 319 participantes são: 176 do sexo masculino $(55,2 \%)$; 172 solteiros $(53,9) \%, 120$ casados $(37,6 \%)$ e 17 divorciados (5,3\%); a faixa etária com maior incidência está entre 21 e 25 anos $(30,4 \%)$, seguida pela de 26 a 30 anos (26,6\%); a escolaridade de $47,8 \%$ dos participantes corresponde ao Ensino Médio completo e de 50,3\%, varia do Ensino Superior incompleto à Pós-Graduação (1,9\% dos respondentes deixou esse item em branco); $27,6 \%$ dos empregados trabalham até 1 ano na organização e 30,7\%, há mais de 3 anos.

A alta taxa de participantes com pouco tempo de serviço decorre principalmente da empresa privada, na qual a rotatividade é bastante elevada no cargo que mais possui funcionários. De acordo com a área de Recursos Humanos, esse fato decorre das atividades e do baixo salário desse cargo.

\section{Instrumentos}

Nesta pesquisa foram utilizadas três escalas validadas: Escala de Bem-Estar Pessoal nas Organizações, Escala de Configurações de Poder Organizacional e Inventário Reduzido dos Cinco Fatores de Personalidade (ICFP-R).

A Escala de Bem-Estar Pessoal nas Organizações contém 15 itens e é unifatorial. É uma escala Likert de cinco pontos, variando de 0 (Nunca) a 4 (Sempre). O instrumento foi aplicado em 250 trabalhadores de diversas organizações para validação e tem se revelado confiável para avaliar o fenômeno ao identificar baixos e altos níveis de bem-estar em várias organizações; suas médias variam entre 1,2 e 3,5. O índice de 
confiabilidade alpha de Cronbach $(\alpha)$ tem variado entre 0,88 e 0,91, em amostras de diferentes organizações (Paz, 2008).

O instrumento de Configurações de Poder Organizacional é uma escala Likert com cinco pontos, variando de 0 (Não se aplica) a 4 (Totalmente aplicável). Após vários ajustes, Paz e Neiva (2005) apresentam uma versão que possui 40 itens, correspondentes às configurações de poder de Mintzberg (1983), que são: Autocracia (6 itens, $\alpha$ de 0,60), Meritocracia (6 itens, $\alpha$ de 0,75), Sistema Autônomo (7 itens, $\alpha$ de 0,78), Missionária ( 6 itens, $\alpha$ de 0,82), Instrumento ( 7 itens, $\alpha$ de $0,85)$ e Arena Política ( 8 itens, $\alpha$ de 0,84 ).

Foi utilizado uma versão simplificada do ICFP-R, desenvolvida por Tróccoli, Vasconcelos e Pasquali (2004). Nesse instrumento, os fatores são denominados: Neuroticismo (19 itens, $\alpha$ de 0,89), Extroversão (12 itens, $\alpha$ de 0,83), Conscienciosidade (20 itens, $\alpha$ de 0,88), Abertura (17 itens, $\alpha$ de 0,82) e Amabilidade (13 itens, $\alpha$ de 0,82). A versão simplificada é utilizada neste estudo para diminuir a quantidade de itens que os participantes deveriam responder. Possui, portanto, 30 sentenças contendo os seis itens com maior carga fatorial (acima de 0,40) em cada fator do ICFP-R, com uma escala Likert de 7 pontos, variando de 1 (Não sou assim) a 7 (Sou exatamente assim).

\section{Procedimento}

De início, as empresas foram contatadas por e-mail e telefone, sendo selecionadas por demonstrarem interesse nos resultados da pesquisa. Em seguida, foi enviada uma carta de apresentação para que os gestores pudessem avaliar o projeto de pesquisa, visando a obter consentimento para a coleta de dados. Foi também realizada uma reunião com os representantes de cada empresa para esclarecer dúvidas e apresentar os questionários, obter informações sobre a operacionalização da coleta e estabelecer compromisso profissional ético.

Após o consentimento, teve início a coleta de dados no próprio local de trabalho de cada empregado. Para a realização da coleta, um representante da empresa acompanhava a pesquisadora apresentando-a aos funcionários; em seguida, a pesquisadora introduzia a pesquisa (objetivo, procedimentos e sigilo) e entregava-lhes o questionário, explicando seu preenchimento e respondendo às dúvidas que surgissem. Cada bloco entregue aos participantes continha a apresentação da pesquisa, o requerimento de dados demográficos e as três escalas anteriormente apresentadas, cuja apresentação sequencial variava de um bloco para o outro. Os questionários eram recolhidos pela própria pesquisadora.

\section{Análise de dados}

Após a coleta de dados, foram excluídos os questionários de 21 participantes da pesquisa, pois possuíam mais da metade de um dos instrumentos em branco. Em seguida, todos os demais questionários foram numerados e digitados em um banco de dados.

As primeiras análises realizadas foram exploratórias, visando identificar e corrigir problemas de digitação, distribuição, casos extremos e dados faltosos. Logo após, com o objetivo de melhor compreender as relações entre as variáveis, foram feitas análises de regressão linear, para verificar a relação de predição das variáveis independentes (configurações de poder) sob a variável dependente (bem-estar). Por fim, foram realizadas análises de regressão múltipla hierárquica, para identificar se as características de personalidade funcionam como mediadoras dessas relações.

Para que seja afirmado que uma variável é mediadora, Baron e Kenny (1986) explicitam três condições: o mediador é preditor significativo da variável dependente; a variável independente é um preditor significativo do mediador; e, na presença da variável independente e do mediador, a relação significativa que existia entre a variável independente e a dependente decresce em magnitude. $O$ teste de moderação foi realizado, não sendo descrito devido à ausência de resultado significativo para essa amostra.

\section{Resultados}

Os primeiros resultados apresentados referem-se às análises de regressão linear entre as configurações de poder (variáveis independentes) e o bem-estar (variável dependente). Em seguida, são apresentadas as análises referentes às três condições de Baron e Kenny (1986) para identificar a relação de mediação das características de personalidade do Modelo dos Cinco Grandes Fatores. A Tabela 1 apresenta o resultado da regressão linear, identificando quais configurações de poder melhor predizem a variável dependente bem-estar.

Tabela 1. Regressão linear entre configurações de poder e bem-estar.

\begin{tabular}{lcccc}
\hline \multirow{2}{*}{ Resumo do modelo } & $\mathbf{R}$ & $\mathbf{R}^{\mathbf{2}}$ & $\begin{array}{c}\mathbf{R}^{\mathbf{2}} \\
\text { Ajustado }\end{array}$ & Sig. \\
\cline { 2 - 5 } & 0,70 & 0,49 & 0,48 & 0,000 \\
\hline Variáveis & $\mathbf{B}$ & Beta & $\mathbf{T}$ & Sig. \\
\hline Instrumento & $-0,095$ & $-0,127$ & $-1,903$ & 0,050 \\
Missionária & 0,222 & 0,247 & 4,313 & 0,000 \\
Sistema Autônomo & 0,310 & 0,402 & 6,330 & 0,000 \\
\hline
\end{tabular}

Nota. Constante: 0,000 .

Na Tabela 1 verifica-se que as configurações que predizem significativamente o bem-estar são missionária e sistema autônomo, de forma positiva, e instrumento, de forma negativa. Juntas, as variáveis de configurações de poder explicam $49 \%\left(\mathrm{R}^{2}\right)$ da variável bem-estar, sendo esta uma porcentagem bastante relevante. Quanto à força dessas variáveis para predizer o bem-estar, a configuração sistema autônomo é a mais forte delas (Beta $=0,402)$, seguida de missionária $($ Beta $=0,247)$ e de instrumento $($ Beta $=-0,127)$, sendo esta última negativa.

Quanto ao teste de mediação, foram testadas as três condições citadas por Baron e Kenny (1986). A primeira delas afirma que a variável mediadora (características de personalidade) deve ser preditora da variável dependente 
Tabela 2. Relações entre a variável independente missionária, a mediadora conscienciosidade e a dependente bem-estar.

\begin{tabular}{|c|c|c|c|c|}
\hline Variáveis Independentes e Mediadora & $\begin{array}{c}\text { Variável } \\
\text { dependente }\end{array}$ & $\mathbf{R}^{2}$ & Beta & Sig. \\
\hline Missionária* & & 0,353 & 0,594 & 0,000 \\
\hline Missionária* & Bem-estar & 0,353 & 0,580 & 0,000 \\
\hline Conscienciosidade** & & 0,367 & 0,120 & 0,008 \\
\hline
\end{tabular}

Nota: *Variável independente; **Variável mediadora; F1 = 172,520; F2 =91,419.

Tabela 3. Relações entre as variável independente instrumento, a variável mediadora conscienciosidade e a variável dependente bem-estar.

\begin{tabular}{lllll}
\hline Variáveis & Variável dependente & $\mathbf{R}^{\mathbf{2}}$ & Beta & Sig. \\
\hline Instrumento* & & 0,221 & $-0,470$ & 0,000 \\
\cline { 3 - 6 } Instrumento* & Bem-estar & 0,221 & $-0,452$ & 0,000 \\
Conscienciosidade** & & 0,236 & 0,124 & 0,014 \\
\hline
\end{tabular}

Nota: *Variável independente; **Variável mediadora; F1 = 89,63; F2 = 48,63.

(bem-estar). Nesse caso, somente a variável conscienciosidade é preditora significativa de bem-estar pessoal nas organizações $\left(\mathrm{R}^{2}=0,035 ;\right.$ Beta $\left.=0,188 ; \operatorname{Sig} \leq 0,01\right)$.

Para a segunda condição é necessário que as variáveis independentes (configurações de poder) predigam a variável mediadora (conscienciosidade). $\mathrm{O}$ teste de regressão indica que somente as configurações missionária $\left(\mathrm{R}^{2}=0,014\right.$; Beta $=0,118 ; \operatorname{Sig} \leq 0,05)$ e instrumento $\left(R^{2}=0,020 ;\right.$ Beta $=-0,143$; Sig $\leq 0,05)$ predizem essa característica de personalidade, sendo a primeira uma relação positiva e a segunda uma relação negativa.

Por fim, a terceira condição afirma que, na presença da variável independente e do mediador, a relação significativa que existia entre a variável independente e a dependente decresce em magnitude. A Tabela 2 apresenta o teste de mediação para a variável independente missionária. Os resultados indicam que, na presença da variável conscienciosidade, a relação entre a configuração missionária e o bem-estar decresce em magnitude (o Beta diminui de 0,594 para 0,580 ) e o poder de explicação do bem-estar aumenta (o $\mathrm{R}^{2}$ passa de 0,353 para 0,367), ou seja, há relação de mediação.

O mesmo ocorre para a variável independente instrumento (o Beta diminui de $-0,470$ para 0,452 ; o $\mathrm{R}^{2}$ passa de 0,221 para 0,236). Esses resultados são apresentados na Tabela 3.

Uma síntese dos resultados é apresentada na Figura 1, cujas linhas contínuas representam relações positivas e as linhas interrompidas representam as relações negativas. Todas as relações descritas são significativas ( $\operatorname{Sig} \leq 0,05)$.

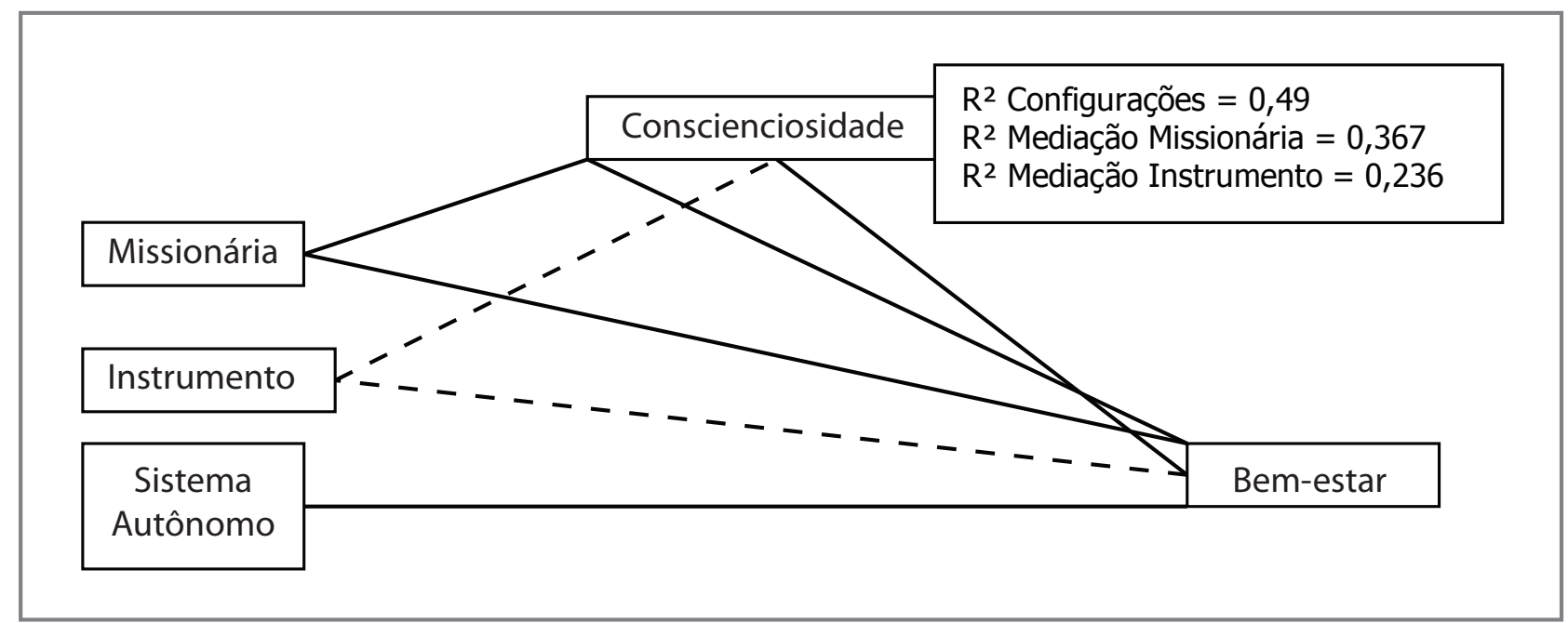

Figura 1. Relações entre as configurações missionária, instrumento e sistema autônomo (variáveis independentes), o bem-estar (variável dependente) e a característica de personalidade conscienciosidade (variável mediadora). 


\section{Discussão}

A análise sobre quais configurações de poder predizem a variável bem-estar indicou uma relação positiva com as variáveis missionária e sistema autônomo, e uma negativa com instrumento. Isto significa que, para essa amostra, quanto mais os indivíduos percebem as configurações sistema autônomo e missionária, mais experienciam bem-estar no trabalho. No segundo caso, observa-se o oposto, isto é, quanto maior a percepção da configuração instrumento, menor é o bem-estar pessoal.

A organização que apresenta a característica de um sistema autônomo retrata maior flexibilidade e hierarquia mais achatada (Mintzberg, 1983). Nela, também há mais espaço para análises e críticas por parte dos membros e o controle exercido por meio de metas (Paz, 2004). Sendo assim, essas características podem contribuir para um maior bem-estar, pois geralmente são organizações que oferecem mais possibilidades de crescimento e reconhecimento pessoal, além de adotarem estratégias para evitar que influenciadores externos interfiram no seu cotidiano, dificultando que objetivos de poderosos que estão fora da organização perturbem o seu funcionamento. A dinâmica da organização depende mais dela mesma, dos seus membros componentes, refletindo mais maturidade.

Por exemplo, o reconhecimento pessoal pode advir das recompensas utilizadas e valorizadas nessa configuração. Além disto, a estrutura mais flexível favorece a percepção de autonomia, que, por sua vez, está relacionada à liberdade que o indivíduo possui para utilizar seu estilo pessoal na execução de seu trabalho.

A organização vista como missionária tem uma forte ideologia que promove a identificação dos membros com a sua missão e busca incentivar uma participação 'apaixonada' destes na organização (Mintzberg, 1983). Quanto mais forte é essa configuração, maior é o coletivismo, menor é a departamentalização e há menos treinamentos formais.

Possuem também a preocupação em servir à comunidade e o compromisso com o bem comum e o atendimento das necessidades dos indivíduos de uma sociedade, beneficiando-os direta e indiretamente. Essas são características que, de acordo com Wells (2004), fazem parte de muitas instituições publicas e que podem favorecer o bem-estar, especialmente para aqueles que têm compromisso com essa ideologia.

Ainda sobre a análise de quais configurações de poder predizem a variável bem-estar, tem-se uma relação negativa com a configuração instrumento, em que a organização seria um meio para que os influenciadores externos alcançassem seus objetivos. Há bastante burocratização e uma hierarquia rígida para ajudar no controle do comportamento dos empregados (Mintzberg, 1983), o que pode ir de encontro ao polo gratificação do bem-estar.

Em primeiro lugar, como os objetivos na organização instrumento são os de pessoas que se encontram fora dela, os membros podem não compreender o sentido de decisões que são tomadas ou mesmo não sentir que participam das mesmas. Em segundo, os trabalhadores podem não possuir espaço para se colocarem, devido à grande burocratização e estrutura rígida da empresa. É provável que essas carac- terísticas estejam relacionadas à diminuição da percepção de bem-estar dos mesmos.

A configuração instrumento também é bastante comum em organizações públicas, já que estas funcionam como um meio do governo atingir seus objetivos. Em se tratando do ambiente político em que o país vive, o partido do governo exerce grande influência no aparelho do estado, sendo possível observar, muitas vezes, maior compromisso partidário que organizacional.

Contudo, uma nova forma de enxergar as instituições políticas, denominada neo-institucionalismo, está sendo discutida. O neo-institucionalismo não nega a importância do contexto social da política e dos atores individuais, mas já insiste na ideia de um papel mais autônomo para as instituições políticas e reivindica que a "autonomia é necessária para estabelecer que as instituições políticas sejam mais do que simples espelhos de forças sociais" (March \& Olsen, 2008, p. 127).

Para verificar a relação de mediação das características de personalidade, três condições foram necessárias (Baron \& Kenny, 1986). A primeira delas demonstrou que conscienciosidade prediz bem-estar. Isto significa que aquelas pessoas com alto grau dessa característica, que tendem a se perceber como mais organizadas, persistentes, decididas e ambiciosas, possuem maior bem-estar no trabalho. Esses traços podem estar levando os indivíduos a lutarem mais e a alcançarem mais seus objetivos, tornando-os mais felizes com a organização, uma vez que esta possibilita a realização de algumas de suas ambições. Resultado semelhante foi observado por Neubert (2004), que encontrou uma relação positiva entre conscienciosidade e satisfação no trabalho.

A segunda condição refere-se à necessidade das variáveis independentes predizerem a variável mediadora. Esta análise faz sentido, pois, de acordo com alguns autores (Banks, 1992), tanto o indivíduo pode mudar a organização como a organização pode mudar o indivíduo.

A relação entre configuração missionária e a característica conscienciosidade acontece de forma positiva, ou seja, quanto mais os funcionários percebem essa configuração, mais conscienciosos são. Uma possível razão para esse fato está na pouca autocracia e na grande participação que a configuração missionária oferece. Nesse sentido, quanto mais o indivíduo percebe que há espaço na empresa para lutar pelo que acredita, mais o faz. Além disso, o próprio princípio que envolve a organização missionária sugere que o trabalhador acredite, persista e lute pela ideologia, perdendo o sentido quando isso não acontece.

Por outro lado, a relação entre a configuração instrumento e a característica conscienciosidade é negativa, o que indica que quanto maior a percepção da empresa como instrumento, menos conscienciosos são os funcionários. Isso mostra que quando os funcionários enxergam a organização como um meio para que influenciadores de fora alcancem seus objetivos, mais se tornam descuidados, negligentes e sem objetivos claros. Esta relação pode ocorrer, pois os mesmos não veem razão para serem conscienciosos devido à burocracia, estrutura rígida e objetivos que vêm de fora. Esse contexto pode contribuir para que os indivíduos não lutem nem persistam, pois não possuem espaço nem possibilidade de alcançarem o que desejam. 
Por fim, quanto à terceira condição, a característica de personalidade conscienciosidade medeia a relação entre ambas as configurações e bem-estar. Como resultado, a relação positiva entre missionária e bem-estar no trabalho aumenta quanto mais consciencioso o indivíduo se perceber. Ou seja, aqueles que identificam a ideologia da organização de forma mais forte, lutam e persistem por ela, e sentem-se bem ao desempenhar o trabalho que desenvolvem naquela organização.

A relação negativa entre instrumento e bem-estar também é mediada pela percepção de conscienciosidade. Isso indica que quanto mais o indivíduo percebe a organização em que trabalha como um instrumento para que influenciadores externos alcancem seus objetivos (configuração de poder instrumento), menos lutará pelos seus objetivos e ambições (característica de personalidade conscienciosidade), tendo seu bem-estar diminuído.

Conclui-se que os resultados obtidos contribuem para a compreensão do bem-estar nas organizações, pois dão indícios de algumas variáveis que podem impactar no mesmo, como as configurações de poder e a personalidade. No entanto, enfatiza-se a necessidade de explorar mais esse tema, do ponto de vista empírico e conceitual. Sem sombra de dúvida, outros estudos investigando organizações com diferentes configurações de poder complementariam os resultados aqui descritos. Além disso, a relação do bem-estar com outras variáveis do nível organizacional poderiam ser testadas, de forma a melhor identificar o papel que as variáveis macro têm no bem-estar pessoal nesse contexto de trabalho.

Outro ponto que deve ser enfatizado refere-se à generalização dos resultados, que foram coletados em apenas duas organizações (uma pública e uma privada) e, portanto, podem estar relacionados ao contexto especifico dessas organizações. Sendo assim, os resultados aqui discutidos dão indícios de relações entre as variáveis investigadas, mas são necessários outros estudos em diferentes organizações para que os resultados possam ser generalizados.

\section{Referências}

Albuquerque, A. S. (2004). Bem-estar subjetivo e sua relação com personalidade, coping, suporte social, satisfação conjugal e satisfação no trabalho. Tese de Doutorado, Universidade de Brasília, Brasília.

Allik, J., \& McCrae, R. R. (2002). A five-factor theory perspective. Em R. R. McCrae \& J. Allik (Orgs.), The five-factor model of personality across cultures (pp. 303-321). New York: Kluwer Academic/Plenum.

Andrade, J. M. (2008). Evidências de validade do inventário dos cinco grandes fatores de personalidade para o Brasil. Tese de Doutorado, Universidade de Brasília, Brasília.

Banks, M. H. (1992). Desempleo e salud mental: investigaciones britânicas recientes. Em J. L. Álvaro, J. R. Torregrosa \& A. G. Luque (Orgs.), Influencias sociales y psicológicas en la salud mental (pp. 143-170). Madrid: Siglo Veintiuno de España.

Baron, R. M., \& Kenny, D. A. (1986). The moderator-mediator variable distinction in social psychological research: Conceptual, strategic, and statistical considerations. Journal of Personality and Social Psychology, 51, 1173-1182.
Daniels, K. (2000). Measures of five aspects of affective wellbeing at work. Human Relations, 53, 275-294.

Danna, K., \& Griffin, R. W. (1999). Healthy and well being in the workplace: A review and synthesis of the literature. Journal of Management, 25, 357-384. Retirado em 20/08/2004 do BNET, de http://www.findarticles.com/.

Deci, E. L., \& Ryan, R. M. (2008). Hedonia, eudaimonia, and well-being: An introduction. Journal of Happiness Studies, 9, 1-11.

Diener, E. (1984). Subjective well-being. Psychological Bulletin, 95, 542-575.

Diener, E. (2000). Subjective well-being: The science of happiness and a proposal for a national index. American Psychologist, 55, 34-43.

Diener, E., Suh, E. M., Lucas, R. E., \& Smith, H. L. (1999). Subjective well-being: Three decades of progress. Psychological Bulletin, 125, 276-302.

Ferreira, M. C., Pacheco, S., Pinto, N. M., Fernandes, H. A., \& Silva, A. P. C. (2007). O bem-estar no trabalho e a predição de exaustão emocional. Em Associação Nacional de PósGraduação e Pesquisa em Administração (Org.), Anais do XXXI ENANPAD. Rio de Janeiro: ANPAD. Retirado em 01/07/2008, de http://www.anpad.org.br/evento.php?acao=trabalho\&cod edicao_subsecao $=280 \&$ cod_evento_edicao $=33 \&$ cod_edicao_ trabalho $=7334$.

Gosendo, E., \& Paz, M.G.T. (prelo). Justiça organizacional e seu papel de mediação entre o estilo de funcionamento organizacional e o bem-estar do trabalhador. Em M. G. T. Paz (Org.), O poder da estrutura e das subjetividades na cultura organizacional.

Howard, P. J., \& Howard, J. M. (1995). The Big Five quick start: An introduction to the Five-Factor Model of personality for human resource professionals. Retirado em 20/04/2004, de http://eric.ed.gov/ERICWebPortal/custom/portlets/ recordDetails/detailmini.jsp?_nfpb=true\&_\&ERICExtSearch_ SearchValue_0 $=$ ED 384754\&ERICExtSearch_SearchType_ $0=$ n o\&accno=ED384754.

Hutz, C. S., Nunes, C. H., Silveira, A. D., Serra, J., Anton, M., \& Wiekzorek, L. S. (1998). O desenvolvimento de marcadores para a avaliação da personalidade no modelo dos cinco grandes fatores. Psicologia: Reflexão e Crítica, 11, 395-411.

March, J. G., \& Olsen, J. P. (2008). Neo-institucionalismo: fatores organizacionais na vida política. Revista de Sociologia e Política, 16, 121-142.

Martins, J. L. T. P., \& Paz, M. G. T. (2000). Poder e comprometimento em tempo de mudança organizacional: estudo de caso de uma empresa pública de serviços de informática. Revista de Administração - RAE, 35, 61-71.

McCrae, R. R., \& Terracciano, A. (2005) Personality profiles of cultures: Aggregate personality traits. Journal of Personality and Social Psychology, 89, 407-425.

Meleiro, A. R., \& Siqueira, M. M. M. (2005). Os impactos do suporte do supervisor e de estilos de liderança sobre bem-estar no trabalho. Em Associação Nacional de PósGraduação e Pesquisa em Administração (Org.), Anais do XXIX ENANPAD. Brasília: ANPAD. Retirado em 01/07/2008, de http://www.anpad.org.br/evento.php?acao=trabalho\&cod edicao_subsecao $=30 \&$ cod_evento_edicao $=9 \&$ cod_edicao_ trabalho $=225$.

Mintzberg, H. (1983). Power in and around organizations. New York: Prentice Hall. 
Neiva, E. R. (1999). Estudo da influência pessoal nas organizações: comparação entre a autopercepção e a percepção do outro no contexto do poder organizacional. Dissertação de Mestrado, Universidade de Brasília, Brasília.

Neubert, S. P. (2004). The Five-Factor Model of personality in the workplace. Retirado em 20/04/2005, de, www.personalityresearch. org/papers/neubert.html.

Nunes, C. H. S., Hutz, C. S., \& Giacomoni, C. H. (2009). Associação entre bem-estar subjetivo e personalidade no modelo dos cinco grandes fatores. Avaliação Psicológica, 8, 99-108.

Paschoal, T. (2008). Bem-estar no trabalho: relações com suporte organizacional, prioridades axiológicas e oportunidades de alcance de valores pessoais no trabalho. Tese de Doutorado, Universidade de Brasília, Brasília.

Paz, M. G. T. (2004). Poder e saúde organizacional. Em A. Tamayo (Org.), Cultura e saúde nas organizações (pp. 127-154). Porto Alegre: Artmed.

Paz, M. G. T. (2008). Bem-estar pessoal nas organizações: construção e validação de um instrumento de medida [Texto não publicado].

Paz, M. G. T., \& Neiva, E. R. (2005). Construção e validação de uma escala de configurações de poder nas organizações [Manuscrito submetido à publicação].

Ryff, C. D. (1989). Happiness is everything, or is it? Explorations on the meaning of psychological well-being. Journal of Personality and Social Psychology, 57, 1069-1081.

Siqueira, M. M. M., \& Padovam, V. A. R. (2008). Bases teóricas de bem-estar subjetivo, bem-estar psicológico e bem-estar no trabalho. Psicologia: Teoria e Pesquisa, 24, 201-209.
Souto, S. O., \& Rego, J. A. (2007). Como as percepções de espírito de camaradagem explicam a felicidade dos colaboradores: o papel moderador da necessidade de pertença. Em Associação Nacional de Pós-Graduação e Pesquisa em Administração (Org.), Anais do XXXI ENANPAD. Rio de Janeiro: ANPAD. Retirado em 01/07/2008, de http://www.anpad.org.br/evento. php acao $=$ trabalho\&cod_edicao_subsecao $=280 \&$ cod_evento_ edicao $=33 \&$ cod_edicao_trabalho $=7524$.

Tamayo, A. (2004). Introdução. Em A. Tamayo (Org.), Cultura e saúde nas organizações (pp. 11-16). Porto Alegre: Artmed.

Tróccoli, B. T., Vasconcelos, T. S., \& Pasquali, L. (2004). ICFP-R - Inventário Reduzido dos Cinco Grandes Fatores de Personalidade: Manual Técnico e de Aplicação. LabPAM, Universidade de Brasília, Brasília.

Van Horn, J. E., Taris, T. W., Schaufeli, W. B., \& Scheurs, P. J. G. (2004). The structure of occupational well-being: A study among Dutch teachers. Journal of occupational and Organizational Psychology, 77, 365-375.

Warr, P. B. (2007). Work, happiness and unhappiness. New Jersey: Lawrence Erlbaum Associates.

Recebido em 08.12 .08

Primeira decisão editorial em 29.07.09

Versão final em 01.10 .09

Aceito em 11.01.10 